\title{
Robert Elliot Silberglied
}

This issue of Psyche is dedicated to the memory of Robert E. Silberglied, a victim of the Air Florida accident in Washington, D.C., on January 13, 1982.

Born in Brooklyn, N.Y., in 1946, Bob was already an enthusiastic naturalist and entomologist even in his school days. He graduated from Cornell University in 1967 and received his $\mathrm{PhD}$ from Harvard in 1973. He remained at Harvard until July of 1981, as Assistant Professor and later as Associate Professor in the Department of Biology, teaching mainly the courses in entomology that I had given for many years as his predecessor. He was also Assistant Curator and later Associate Curator in the Entomology Department of the Museum of Comparative Zoology. During the same period he was associated with the Smithsonian Tropical Research Institute, spending about half of each year in Panama or other parts of the American tropics. At the time of his death he was Staff Scientist (Research Entomologist) at the Institute.

Bob joined our society on his arrival in Cambridge in 1968 and for the next 14 years he was one of our most active and enthusiastic members. He served as vice-president and president, and was a member of the editorial board of Psyche for the past decade. At our fall and winter meetings, he could always be depended upon to relate some unusual collecting experience or to demonstrate with superb photographs and specimens some of the remarkable insects that he had collected in the tropics. He combined a warm and sympathetic personality with a brilliant and imaginative mind. In both respects he has left a lasting impression on our society and its members.

The Smithsonian Institution has established the Robert E. Silberglied Memorial Fund to support student research and training in tropical entomology. Those who wish to contribute a gift of any size may send it to: Robert E. Silberglied Memorial Fund, Accounting Office, Smithsonian Institution, L'Enfant 3500, Washington D.C. 20560.

Frank M. Carpenter, editor 


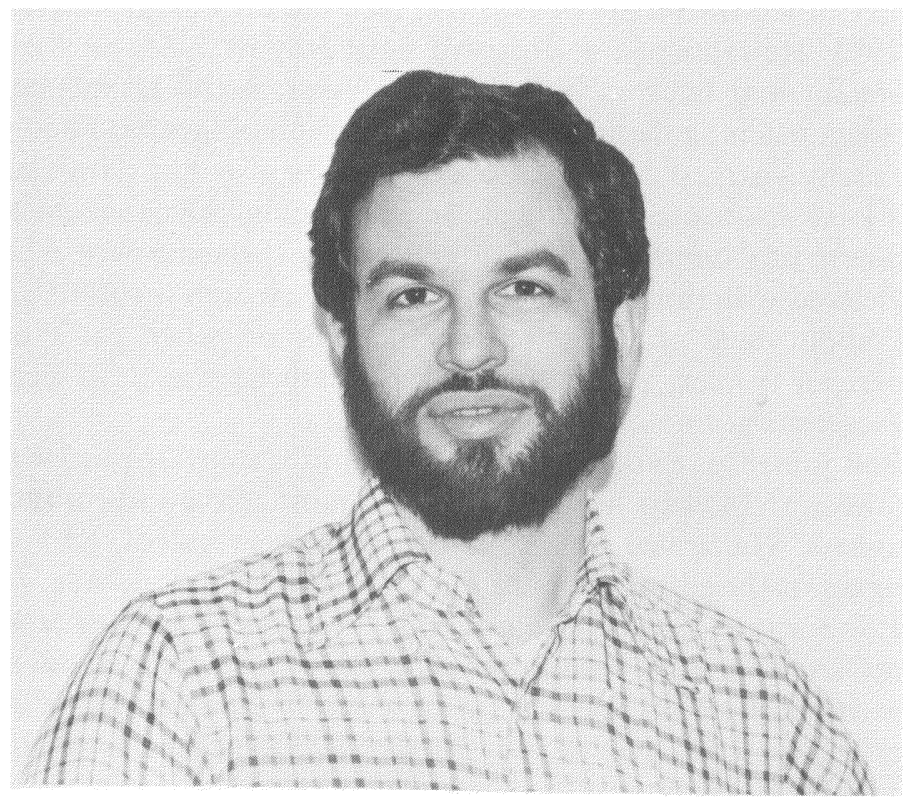

\section{Robert Elliot Silberglied}

Photograph taken in 1981 

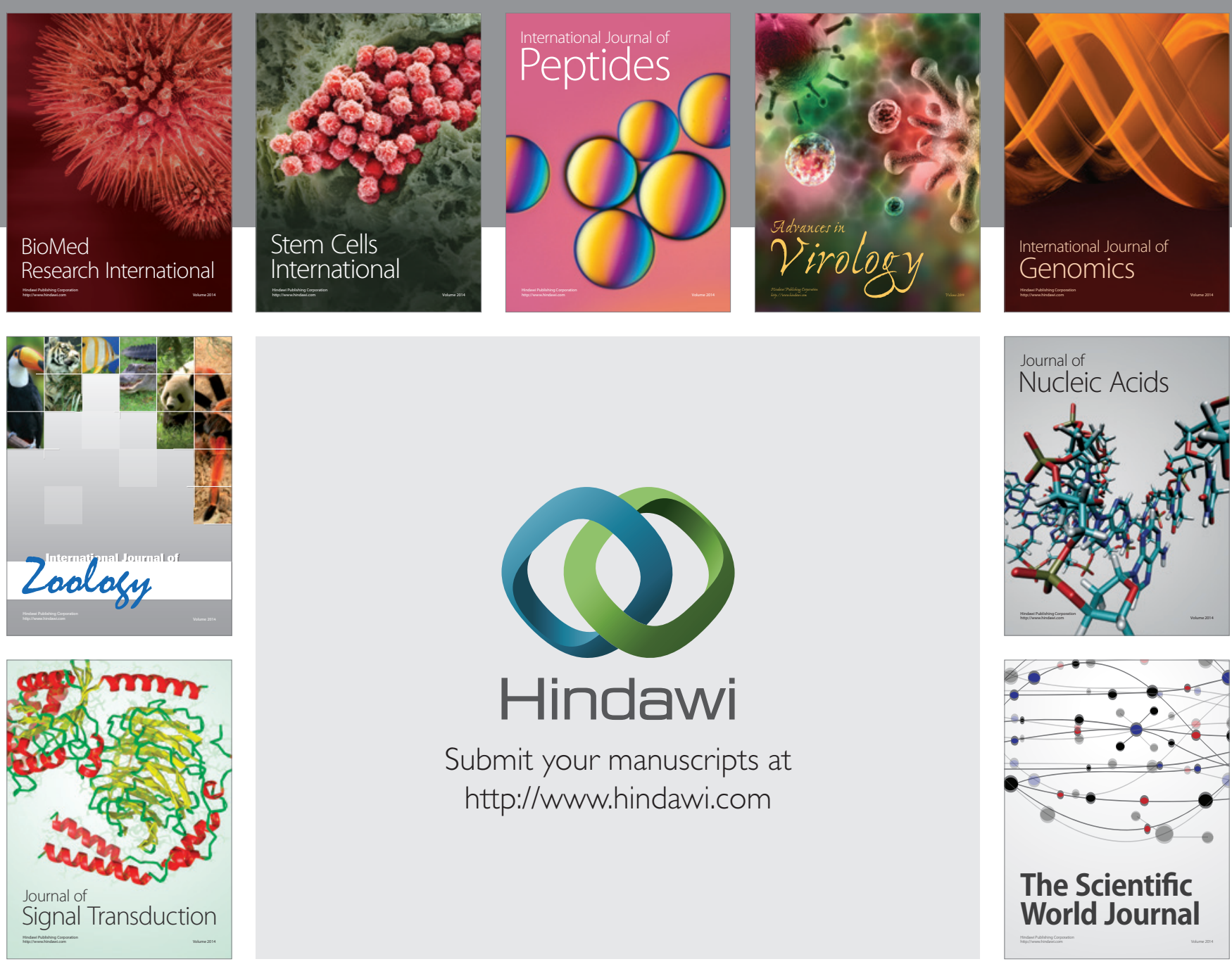

Submit your manuscripts at

http://www.hindawi.com
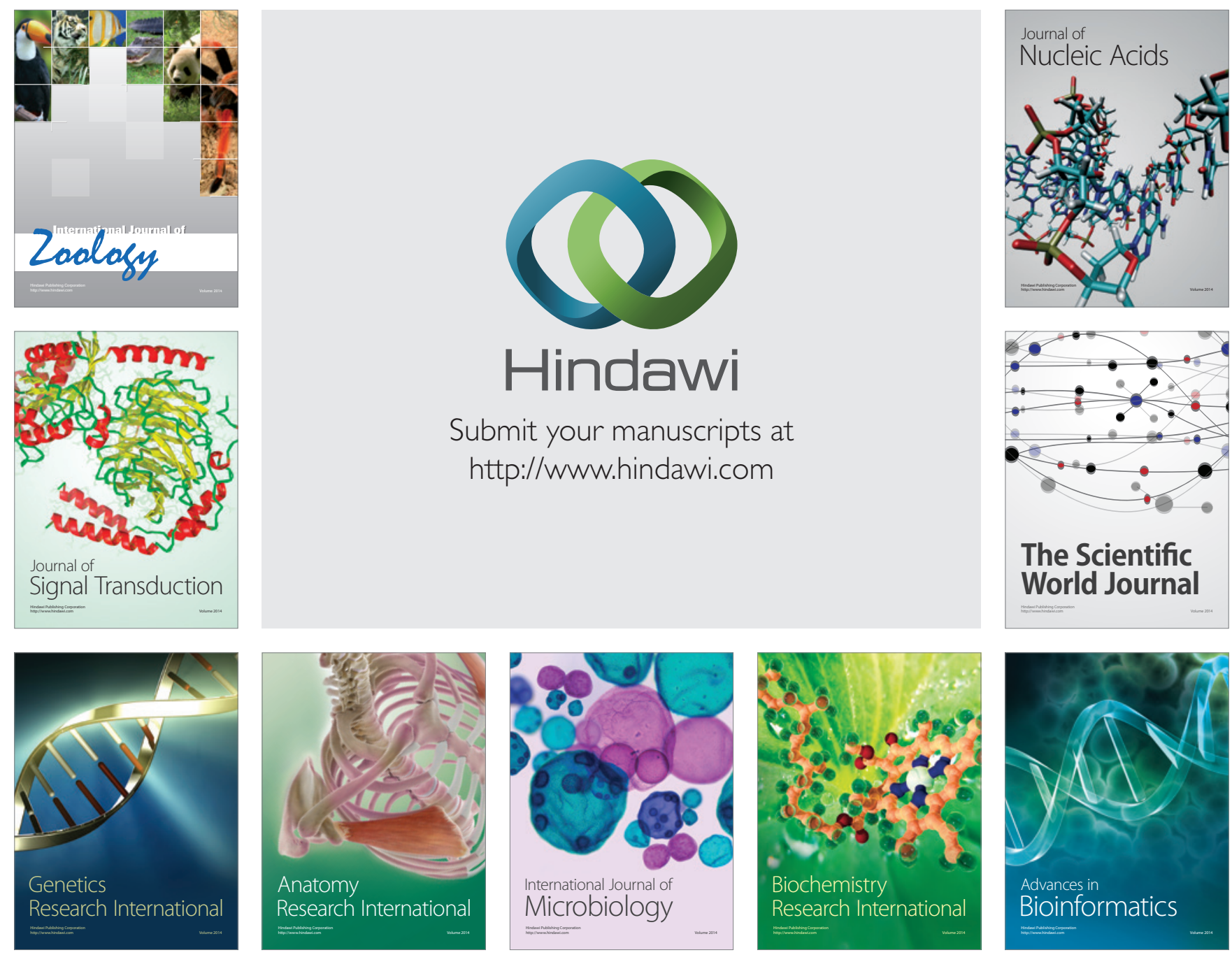

The Scientific World Journal
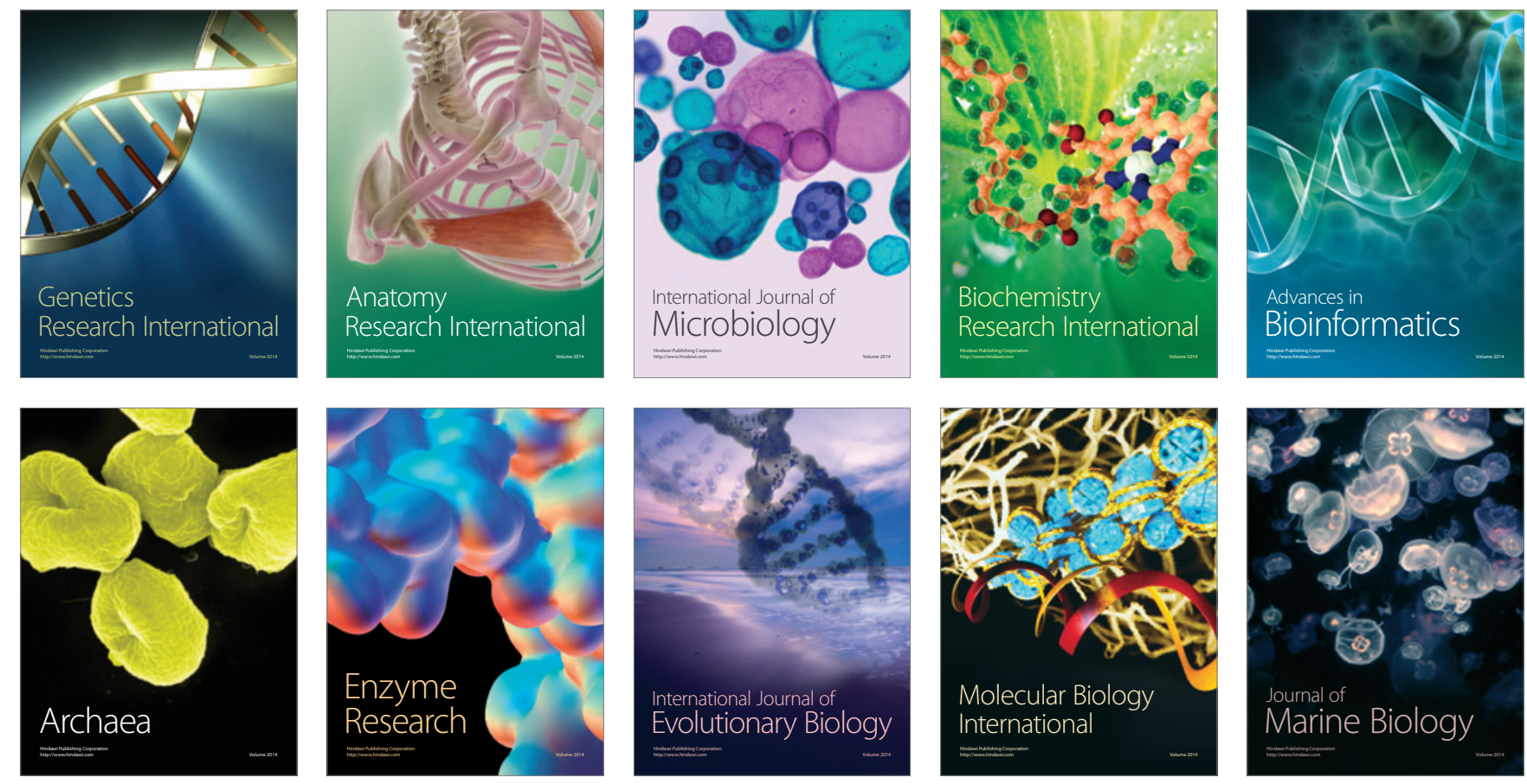